Article

\title{
Transparent Cellulose/Technical Lignin Composite Films for Advanced Packaging
}

\author{
Yujie Guo ${ }^{1}$, Dong Tian ${ }^{1,2, * \mathbb{D}}$, Fei Shen ${ }^{1}$, Gang Yang ${ }^{1}$, Lulu Long ${ }^{1}$, Jinsong He ${ }^{1}$, Chun Song ${ }^{1}$, \\ Jing Zhang ${ }^{1}$, Ying Zhu ${ }^{1}$, Churui Huang ${ }^{1}$ and Shihuai Deng ${ }^{1}$ \\ 1 Institute of Ecological and Environmental Sciences, Sichuan Agricultural University, \\ Chengdu 611130, Sichuan, China \\ 2 State Key Laboratory of Polymer Materials Engineering, Polymer Research Institute of Sichuan University, \\ Chengdu 610065, Sichuan, China \\ * Correspondence: dongtian@sicau.edu.cn; Tel.: +86-28-8629-3087
}

Received: 15 August 2019; Accepted: 2 September 2019; Published: 5 September 2019

\begin{abstract}
Although recent work has shown natural lignin products are promising to fabricate various polymer based functional composites, high-value applications were challenged by their structural complexity and inhomogeneity. This work specially assessed the potential of four technical lignins for cellulose based functional films production. These four technical lignins were obtained by emerging pretreatment systems, i.e., lactic acid-betaine deep eutectic solvent (DES), ethanol organosolv, soda/anthraquinone (Soda/AQ) and the sodium salicylate hydrotrope, and their phenolic substructures were comparatively identified by prevalent ${ }^{31} \mathrm{P}$ NMR technique. The influence of lignin chemical structure on the antioxidant potential and UV-shielding performance of the prepared cellulose/technical lignin composite films were assessed. Results showed severe organosolv and soda/AQ pretreatment produced technical lignins with higher total phenolic hydroxyl groups ( 3.37 and $3.23 \mathrm{mmol}$ g-1 respectively), which also exhibited higher antioxidant activities. The composite films could effectively block the ultraviolet lights especially for UVB region (ultraviolet B, 280-315 nm) at only $5 \mathrm{wt} . \%$ lignin content. The contribution of lignin phenolic substructures to both antioxidant activity and UV-shielding property from high to low was syringyl > guaiacyl $>p$-hydroxyphenyl phenolic hydroxyl groups. This work provided some useful information that could facilitate upstream lignin extraction or downstream value-added applications.
\end{abstract}

Keywords: lignin; UV-shielding; antioxidant; cellulose film; pretreatment

\section{Introduction}

Traditional packaging materials such as polyethylene and polypropylene are mainly produced from non-renewable petroleum resources which has been causing serious environmental concerns due to their ultimate disposal and non-biodegradability [1]. A promising technical strategy to deal with this challenge is to use natural polymers to replace these synthetic polymers for packaging materials production. Cellulose is the most abundant and renewable biopolymer on the earth. It holds great promise for a wide range of types of materials' fabrication such as cellulose nanofibers, films, hydrogels and aerogels for downstream applications due to their abundance in nature, excellent mechanical properties and biodegradability [2-4]. When cellulose is subjected to a dissolution-casting process, flexible transparent films with excellent barrier properties could be obtained, which are comparable to those of prevalent plastic packaging materials [5]. Therefore, these transparent cellulose films are promising alternatives to synthetic plastics for next-generation packaging materials production.

To enhance the value of packaging materials, additional functionality including antioxidant, antimicrobial and UV-shielding property has been usually introduced by incorporating various 
functional additives into the polymer matrix during the film production process. Although prevalent metal oxides such as titanium dioxide and zinc oxide are promising UV-absorber additives, potential environmental hazards are accompanied when they are disposed after use [6]. In addition, these metal oxides could also catalyze the polymer matrix degradation due to their intrinsic photocatalytic activity [7-9]. Recent research progress has shown that some natural biopolymers that contain phenolic hydroxyl groups could be used as both antioxidants and UV-shielding additives to replace the above metal oxides. Unlike metal oxides that block UV lights though a "reflection" manner, these biopolymers are supposed to block UV lights through absorbing their photon energy, which was further converted to heat with the corresponding functional chromophores [10]. Considering that lignin biopolymer is abundant in phenolic hydroxyl groups and compatible with cellulose, it might be a promising functional additive to endow both antioxidant and UV-shielding functionality to cellulose film towards an advanced composite packaging material.

However, lignin in nature is a highly heterogeneous biopolymer. It is mainly composed of three phenylpropane units (mono-lignols), namely, syringyl (S, sinapyl alcohol), guaiacyl (G, conniferyl alcohol), and p-hydroxyphenyl ( $\mathrm{H}$, p-coumaryl alcohol) [11,12]. The complex and heterogeneous chemical structure challenges its downstream applications especially when it is used as a functional bio-additive in which the content and location of phenolic hydroxyl groups play a determinant role. It has been acknowledged that apart from biomass species, the selected pretreatment route that is used to extract lignin from lignocellulosic biomass in a typical biorefinery is also influential in lignin chemical structure [13]. For example, acid based pretreatment tends to easily cleave $\beta-\mathrm{O}-4^{\prime}$ linkages in lignin but cause severe condensation reactions among aromatics while ethanol based organosolv pretreatment tends to produce lignin with low molecular weight and rather high chemical reactivity [14]. Our previous work has shown that four emerging lignocellulose pretreatment methods, i.e., lactic acid-betaine deep eutectic solvent (DES), ethanol organosolv, green liquor (soda/anthraquinone, soda/AQ) and the sodium salicylate hydrotrope could facilely ease cellulose hydrolysis from steam pretreated poplar wood, while producing a technical lignin faction with varied yields. Incorporating these lignin fractions into cellulose matrix to enhance its antioxidant and UV-shielding performance not only shows new opportunities to produce a cellulose based advanced packaging material, but also adds an additional product stream for the current lignocellulose biorefineries [15].

In the work reported here, the technical potential of preparation of transparent cellulose/technical lignin composite films using prevalent solution-casting method was assessed. Four emerging technical lignins were comparatively assessed for their potential to enhance the antioxidant and UV-shielding properties of the resulting composite films. Since lignin phenolic hydroxyl groups were the corresponding functional groups, the influence of their locations and contents on the antioxidant and UV-shielding performance was particularly investigated after they were analyzed by ${ }^{31} \mathrm{P} N \mathrm{NR}$ technique. To give a better assessment, commercial Kraft lignin was introduced in all the experiments. This work showed a promising way to valorize lignin byproduct through fabricating cellulose/technical lignin composite films for advanced packaging, and also provided useful information for lignin downstream application when it was used as an antioxidant and UV-shielding bio-additive.

\section{Materials and Methods}

\subsection{Materials}

Steam pretreated poplar wood was kindly obtained from Forest Products Biotechnology/Bioenergy Group, Department of Wood Science (University of British Columbia, Vancouver, BC, Canada). Diphenyl-1-picrylhydrazyl (DPPH), 6-hydroxy-2,5,7,8-tetramethylchroman-2-carboxylic acid (Trolox), dimethyl sulfoxide (DMSO), cyclohexanol, anhydrous pyridine, deuterated chloroform, chromium(III) acetylacetonate, 2-chloro-4,4,5,5-tetramethyl-1,3,2-dioxaphospholane (TMDP, Product No. 447536), betain, sodium salicylate, anthraquinone, commercial Kraft lignin (Product No. 370959) and microcrystalline cellulose (Avicel ${ }^{\circledR}$ PH-101) were purchased from Sigma-Aldrich. Other common 
chemicals and organic solvents with analytical grade were purchased from Kelong Chemical Regent Co., Ltd. (Chengdu, China).

\subsection{Lignin Extraction and Characterization}

Lignin extraction was conducted using the two-stage pretreatments, i.e., steam pretreatment followed by DES, soda/AQ, hydrotrope and organosolv according to our previous work [16]. DES was first synthesized by stirring lactic acid and betain at a molar ratio of $2.5: 1$ at $80^{\circ} \mathrm{C}$ until a homogeneous colorless liquid was formed [17]. Then resulting DES was applied for lignin extraction from the steam pretreated poplar substrate under atmosphere pressure. About $10 \mathrm{~g}$ steam pretreated poplar biomass (based on dry weight) and $200 \mathrm{~g}$ DES was transferred to a flat bottom glass flask and heated at $130{ }^{\circ} \mathrm{C}$ for $3 \mathrm{~h}$ on a hot plate with continuous stirring. To remove DES and lignin traces, the resulting cellulose pulp was washed by $30 \mathrm{~mL}$ of acetone-water mixture $(1: 1, v / v)$ twice and then hot water twice [18]. The washes and the darkly-colored solution containing lignin and DES were combined together, then placed in fume hood for two days in order to precipitate the dissolved lignin by evaporating of acetone. Lignin extractions with organosolv [19], soda/AQ [20,21] and hydrotrope [22,23] were conducted at their optimum conditions respectively according to previous study. Briefly, dried $100 \mathrm{~g}$ steam pretreated poplar wood was cooked at $170{ }^{\circ} \mathrm{C}$ for $1 \mathrm{~h}$ (liquid to solid ratio, 7:1). The solvent composition was ethanol/water, $50 / 50$ by weight, $1 \% \mathrm{H}_{2} \mathrm{SO}_{4}$ for Organosolv extraction, sodium carbonate in water ( $14 \%$ active alkali), $0.1 \%$ anthraquinone (AQ) for Soda/AQ extraction and $30 \%$ sodium salicylate in water with $0.17 \%$ formic acid catalyst for hydrotrope extraction respectively. After the pretreatment, the vessels were cooled to room temperature in the water bath. The liquid fractions were then collected through vacuum filtration. Lignin precipitation was conducted by adding hot water 10 times to the filtrate fraction for Organosolv and Hydrotrope process, or adjusting the $\mathrm{pH}$ to 2.0 with concentrated $\mathrm{H}_{2} \mathrm{SO}_{4}$ for Soda/AQ process.

The four lignin precipitates were finally collected on nylon membrane, washed thoroughly with water to $\mathrm{pH}$ neutral, dried in the vacuum oven and stored in a desiccator for further characterization use.

Quantitative ${ }^{31} \mathrm{P}$ NMR spectra were used to analyze various hydroxyl group contents according to previous work $[24,25]$. Approximately $20 \mathrm{mg}$ of various lignin (dry sample) was completely dissolved in $500 \mu \mathrm{L}$ of freshly prepared mixture of anhydrous pyridine and deuterated chloroform $(1.6: 1, v / v)$. Then $100 \mu \mathrm{L}$ of cyclohexanol (10.85 $\mathrm{mg} \mathrm{mL}^{-1}$ in the above pyridine and deuterated chloroform mixture) was added as an internal standard and $100 \mu \mathrm{L}$ of chromium(III) acetylacetonate solution $\left(5 \mathrm{mg} \mathrm{mL}^{-1}\right.$ in the pyridine and deuterated chloroform mixture) was added as the relaxation reagent. Afterward, $100 \mu \mathrm{L}$ phosphitylating reagent (TMDP) was rapidly added. The prepared sample mixture was further transferred to a $5 \mathrm{~mm}$ NMR tube for spectra acquisition (AV II 600, Bruker) [26,27]. The chemical shift of aliphatic - $\mathrm{OH}$, internal standard, Syringyl -OH, Guaiacyl -OH, p-hydroxyphenyl -OH and - $\mathrm{COOH}$ was identified at 145.5-150.0 ppm, 144.7-145.5 ppm, 140.5-144.5 ppm, 138.6-140.4 ppm, 137.3-138.6 ppm and $133.7-136.0 \mathrm{ppm}$ respectively.

\subsection{Preparation of Cellulose/Technical Lignin Composite Films}

An $8 \%(w / w)$ DMAc/ LiCl solvent system was prepared according to previous work [28]. Avicel ${ }^{\circledR}$ PH-101 cellulose was activated by methanol and DMAc from the previous procedure before dissolution. The activated Avicel ${ }^{\circledR} \mathrm{PH}-101$ cellulose was added to the above $8 \%(w / w)$ DMAc/LiCl solvent system with string until a homogeneous transparent solution was obtained.

Next, $0.2 \mathrm{~g}$ of each lignin sample was added into the above cellulose solution to get a final lignin content of $5 \mathrm{wt} . \%$ (cellulose basis), respectively. The resultant mixture was casted on a glass plate and kept at ambient conditions overnight to form a gel-like film. To remove DMAc and $\mathrm{LiCl}$ traces, the gel-like film was washed thoroughly with distilled water for $24 \mathrm{~h}$. Then the obtained cellulose/lignin composite film was dried in a vacuum oven. 


\subsection{Antioxidant Activity and UV-Shielding Measurement}

The free radical scavenging ability of lignin was evaluated according to a published method reported by Delgado-Andrade et al. with a few modifications [29]. Then, $7.4 \mathrm{mg}$ DPPH was dissolved in $100 \mathrm{~mL}$ methanol to obtain an absorbance of 1.8 at $520 \mathrm{~nm}$. Then $200 \mu \mathrm{L}$ lignin solution $\left(0.1-1.0 \mathrm{mg} \mathrm{mL}^{-1}\right.$ in DMSO) was mixed with $1 \mathrm{~mL}$ of $74 \mathrm{mg} \mathrm{L}^{-1} \mathrm{DPPH}$ in methanol and incubated for $1 \mathrm{~h}$ at $30{ }^{\circ} \mathrm{C}$. After the reaction, its absorption at $520 \mathrm{~nm}$ was immediately measured [30,31]. Trolox solutions with different concentrations $\left(0.1-1 \mathrm{mmol} \mathrm{L}^{-1}\right)$ in DMSO were used as the standard. The results were calculated and expressed as $\mu \mathrm{mol}$ equivalents to Trolox per $\mathrm{g}$ of each lignin sample.

The UV-shielding performance of the prepared composite films was tested on a UV-Visible spectrophotometer (U-2910, HITACHI, Tokyo, Japan). The spectra was obtained at a scanning step of $2 \mathrm{~nm}$ from 200 to $800 \mathrm{~nm}$ [32].

\section{Results and Discussion}

The detailed procedure to fabricate the transparent cellulose/technical lignin composite films was shown in Scheme 1. DMAc/LiCl was selected as the processing solvent for demonstrating purpose since it has good solubility for both cellulose and lignin. Four technical lignins, i.e., DES, organosolv, soda/AQ and hydrotrope lignin were extracted and added respectively into cellulose solution in $\mathrm{DMAc} / \mathrm{LiCl}$ with $5 \mathrm{wt}$ \% (based on the weight of dry cellulose). Then the mixed cellulose/lignin solution was casted and solvent-exchanged with water to produce the composite films. It was proposed that the phenolic hydroxyl groups in these technical lignins could easily scavenge active free radicals through an electron transfer process, therefore endowing the composite films with enhanced antioxidant property. The phenolic hydroxyl groups could also shield UV lights through absorbing their photon energy and then converting it to heat, which was further gradually released into the environment without causing the photo-catalytic degradation of cellulose matrix in comparison to metal oxides.

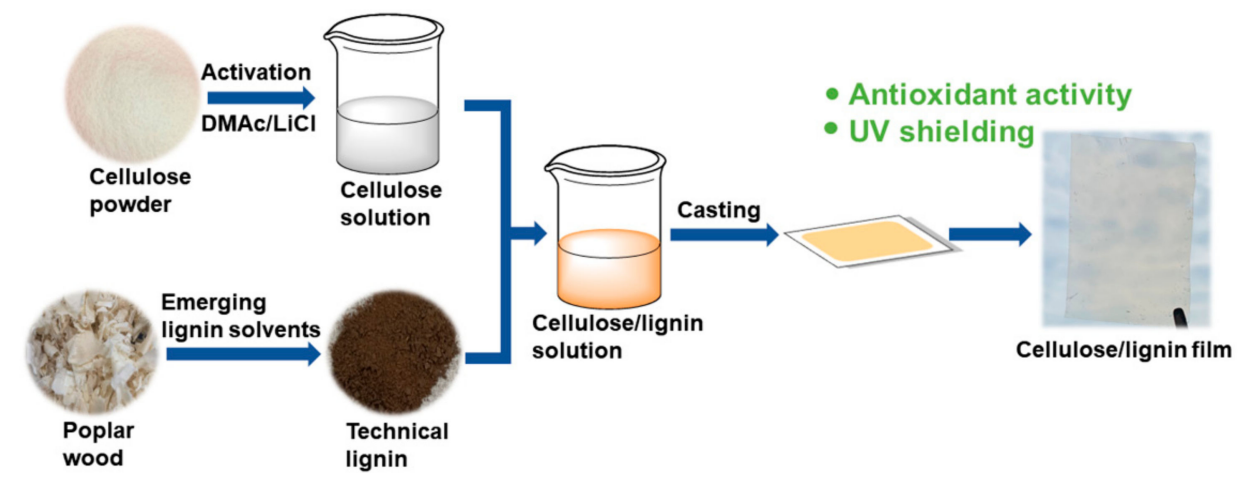

Scheme 1. Procedure to fabricate transparent cellulose/technical lignin composite films with enhanced antioxidant and UV-shielding property. Technical lignins were extracted by deep eutectic solvent, ethanol organosolv, soda/anthraquinone and a hydrotrope respectively at their optimal conditions.

${ }^{31} \mathrm{P}$ NMR spectroscopy is a useful technique to quantitatively analyze various lignin hydroxyl groups [26]. The basic principle is that both the internal standard and the five testing lignin sample are completely soluble and phosphitylated with the phosphorous reagent in the pyridine/deuterated chloroform solvent system, then the phosphorus-labeled hydroxyl groups that belong to lignin including phenolic, aliphatic, and carboxylic hydroxyls could be facilely quantified by ${ }^{31} \mathrm{P}$ NMR spectroscopy [26]. The quantitative ${ }^{31} \mathrm{P}$ NMR spectra of these four technical lignins and Kraft lignin were shown in Figure 1 and the calculated results were presented in Table 1 accordingly. It was apparent that these four technical lignins exhibiting dominant $S$ and $G$ phenolic hydroxyl groups were the HGS (hydroxy-guaiacyl-syringyl)-type hardwood lignin whereas Kraft lignin was the G-type softwood lignin. The structural complexity and heterogeneity of these lignins were evidenced by the multiple peaks in their ${ }^{31} \mathrm{P}$ NMR spectra. It was shown these four extraction solvent systems varied in 
their abilities to alter lignin chemical structures, thus, their ${ }^{31} \mathrm{P} N M R$ spectra were quite different from each other (Figure 1).

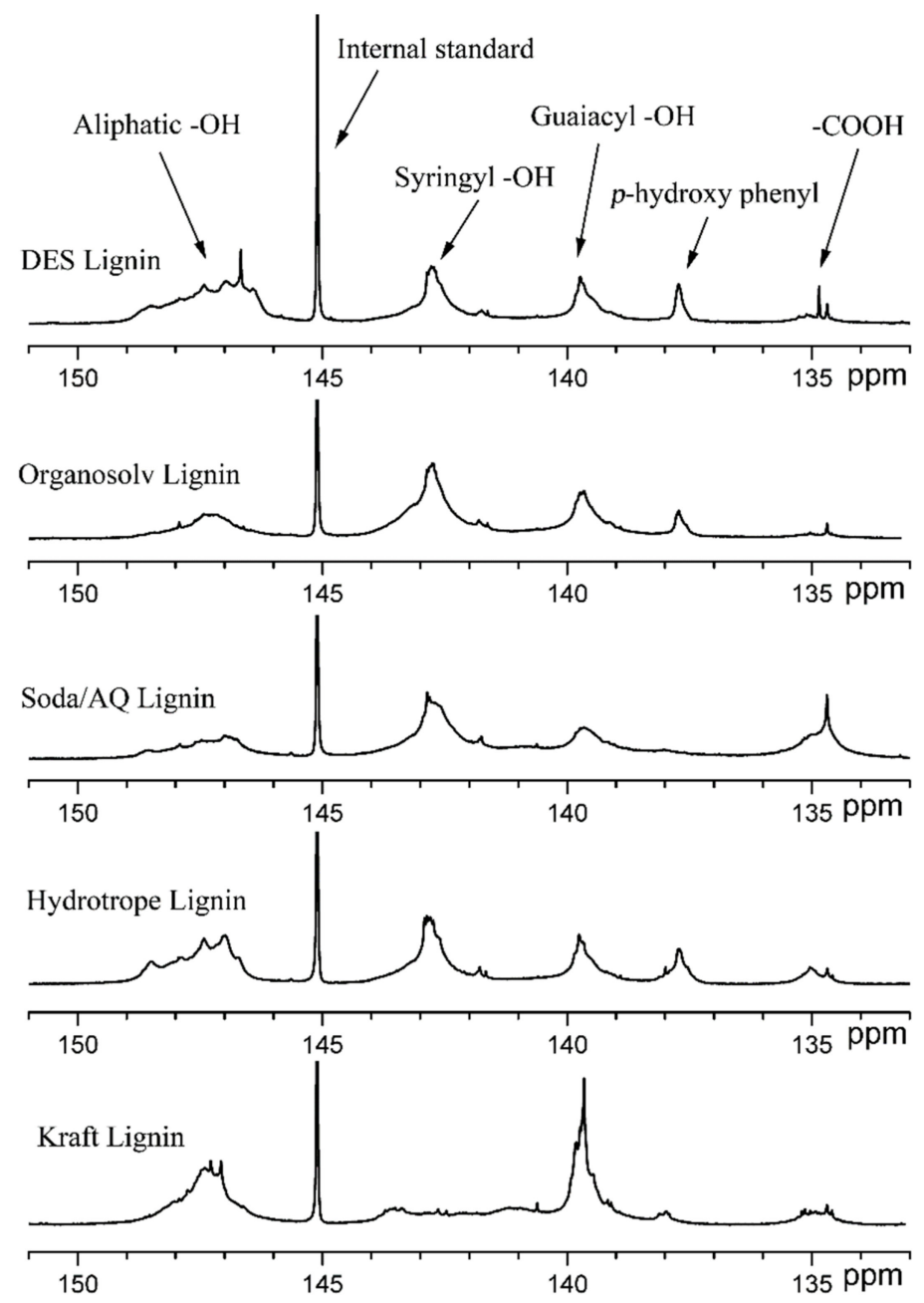

Figure 1. Quantitative ${ }^{31} \mathrm{P}$ NMR spectra of these four technical lignins and Kraft lignin tagged TMDP phosphorous reagent using cyclohexanol as internal standard.

Table 1. Contents and locations of various hydroxyl groups in these five lignins quantified by ${ }^{31} \mathrm{P}$ NMR technique.

\begin{tabular}{cccccc}
\hline -OH Content $\left(\mathbf{m m o l ~ g}^{-1}\right)$ & $\begin{array}{c}\text { DES } \\
\text { Lignin }\end{array}$ & $\begin{array}{c}\text { Organosolv } \\
\text { Lignin }\end{array}$ & $\begin{array}{c}\text { Soda/AQ } \\
\text { Lignin }\end{array}$ & $\begin{array}{c}\text { Hydrotrope } \\
\text { Lignin }\end{array}$ & $\begin{array}{c}\text { Kraft } \\
\text { Lignin }\end{array}$ \\
\hline Aliphatic -OH & 2.40 & 1.04 & 1.17 & 2.00 & 1.98 \\
Syringyl phenolic -OH & 1.31 & 2.03 & 1.92 & 1.63 & 1.02 \\
Guaiacyl phenolic -OH & 0.90 & 1.20 & 1.31 & 1.02 & 2.11 \\
p-hydroxyphenyl -OH & 0.23 & 0.15 & 0.02 & 0.41 & 0.05 \\
Carboxylic acid -OH & 0.18 & 0.09 & 0.87 & 0.32 & 0.37 \\
Total phenolic -OH & 2.44 & 3.37 & 3.25 & 3.06 & 3.18 \\
\hline
\end{tabular}

In a typical lignin extraction process, lignin fragmentation through $\beta-\mathrm{O}-4^{\prime}$ linkages cleavage and lignin condensation among aromatics are two dominant reactions. Lignin fragmentation generates more phenolic units while lignin condensation generates stable carbon-carbon bonds between aromatics [33]. When their total phenolic hydroxyl groups contents were compared (Table 1), it was apparent that mild DES extraction caused lower extent of lignin fragmentation, thus, the resulting DES lignin exhibited a low content of total phenolic hydroxyl groups $\left(2.44 \mathrm{mmol} \mathrm{g}^{-1}\right)$. The other three technical lignins exhibited considerably high contents of total phenolic groups $\left(3.06 \sim 3.37 \mathrm{mmol} \mathrm{g}^{-1}\right)$, which was higher 
or comparable to Kraft lignin $\left(3.18 \mathrm{mmol} \mathrm{g}^{-1}\right)$. In addition to higher extent lignin fragmentation and condensation, severe ethanol organosolv and soda/AQ solvent system also significantly dehydrated aliphatic hydroxyl groups (1.04 and $1.17 \mathrm{mmol} \mathrm{g}^{-1}$ respectively). While soda/AQ process tended to oxidize lignin aromatics through a ring-opening reaction, the resulting technical lignin exhibited much higher content of carboxylic acid hydroxyl groups $\left(0.87 \mathrm{mmol} \mathrm{g}^{-1}\right)$. It was also apparent that the softwood Kraft lignin exhibited much higher content of $G$ phenolic hydroxyl groups $\left(2.11 \mathrm{mmol} \mathrm{g}^{-1}\right)$ in comparison to these four hardwood technical lignins $\left(0.90 \sim 1.31 \mathrm{mmol} \mathrm{g}^{-1}\right)$. From the analysis above, it was shown that the contents and types of phenolic hydroxyl groups in these four technical lignins varied among each other despite the fact that the same starting poplar wood substrate was used. The extraction route selected was highly determinable in lignin chemical structures.

The antioxidant properties of those lignins were further investigated using facile Trolox equivalent antioxidant capacity (TEAC) assessment. The TEAC method employed stable DPPH as the testing radicals and Trolox as the internal standard respectively according to previous reports (Figure 2) [24,29]. The antioxidant activity of these four technical lignins was ranging from 683 to $1382 \mu \mathrm{mol}_{\text {Trolox }} \mathrm{g}^{-1}$ lignin, which was comparable to that of natural phenolic compounds [29,34]. Among these four technical lignins, the antioxidant activity of soda/AQ and organosolv lignin was similar to that of tea polyphenols [35]. The antioxidant activity of DES lignin was still higher than that of some common fruit extracts such as banana and watermelon extract [36]. These results indicated the high feasibility of those technical lignins for the application antioxidant purpose. It was interesting that although organosolv, soda/AQ and Kraft lignin exhibited similar total phenolic hydroxyls groups, their antioxidant activities were quite varied, indicating that the activity of each type of phenolic hydroxyls was dependent. It appeared that syringyl phenolic hydroxyl groups were more responsible for radical-scavenging. When soda/AQ and organosolv lignin were compared, it seemed that the additional carboxylic acid hydroxyl groups in soda/AQ lignin significantly enhanced the overall availability of their phenolic hydroxyls groups, corresponding to an increased antioxidant activity of $1382 \mu \mathrm{mol}_{\text {Trolox }} \mathrm{g}^{-1}$ lignin for soda/AQ lignin.

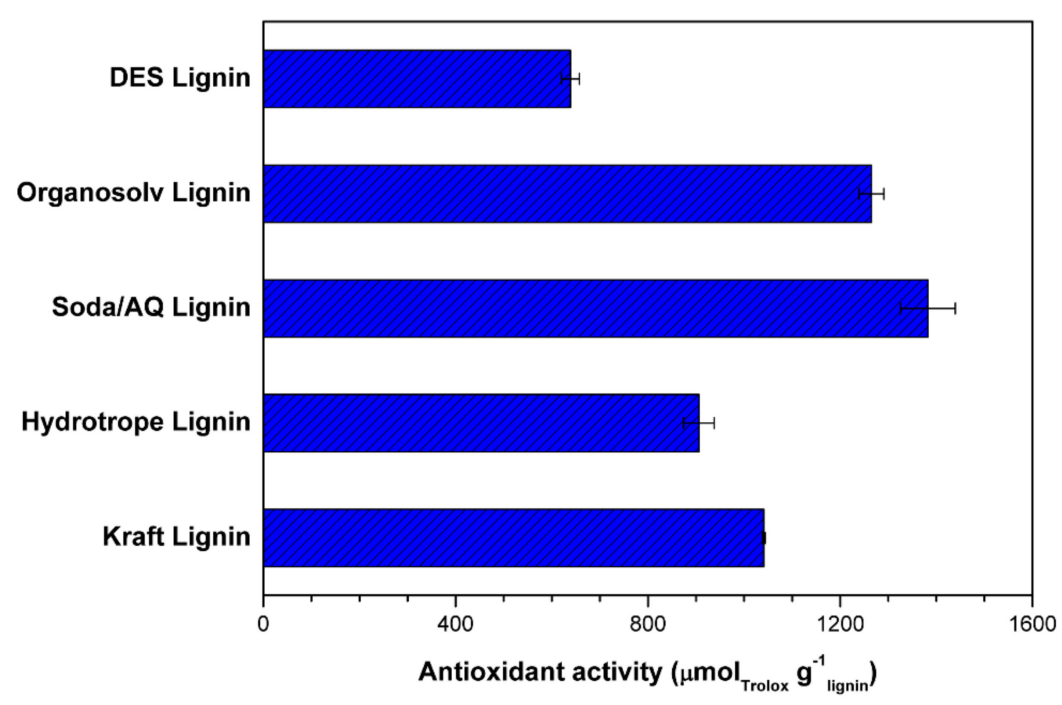

Figure 2. Antioxidant activity of these four technical lignins and Kraft lignin determined by Trolox equivalent antioxidant capacity (TEAC) assay.

Specifically, the antioxidant activity of those five lignins was plotted against their syringyl, guaiacyl, p-hydroxyphenyl and total phenolic hydroxyl groups content respectively to understand which type of phenolic hydroxyl groups was more dominant (Figure 3). It was shown the antioxidant activity was more positively correlated with the content of syringyl phenolic hydroxyl groups $\left(R^{2}=0.6924\right)$, followed by guaiacyl phenolic hydroxyl groups among those five lignins [37]. Furthermore, p-hydroxyphenyl phenolic hydroxyl groups showed limited contribution to antioxidant activity due to their rather low 
content, especially for soda/AQ and Kraft lignin. The overall higher antioxidant activities of those lignins were roughly correlated with their higher total phenolic hydroxyl groups (Figure 3), which was in line with previously reported work that lignin with lower molecular weights tended to show higher antioxidant activity [38]. Although the antioxidation potential of various lignins have been extensively explored recently, results reported here suggest that lignin with higher syringyl units is more promising.

(a)

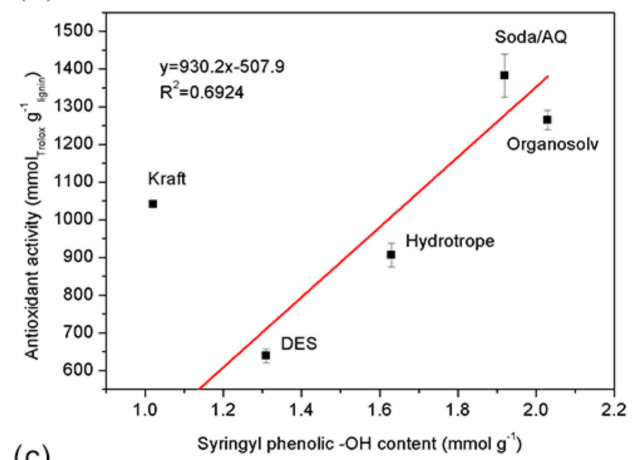

(c)

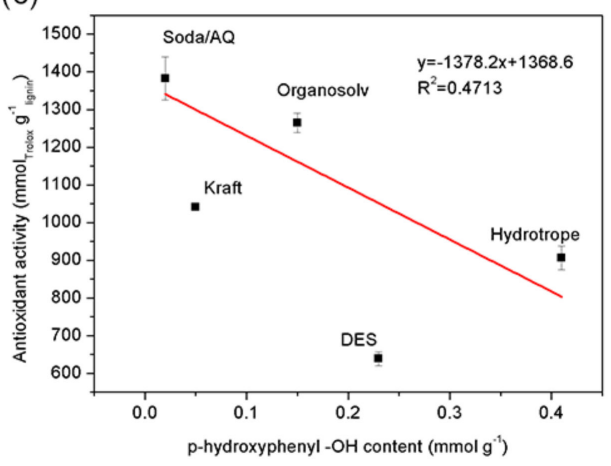

(b)

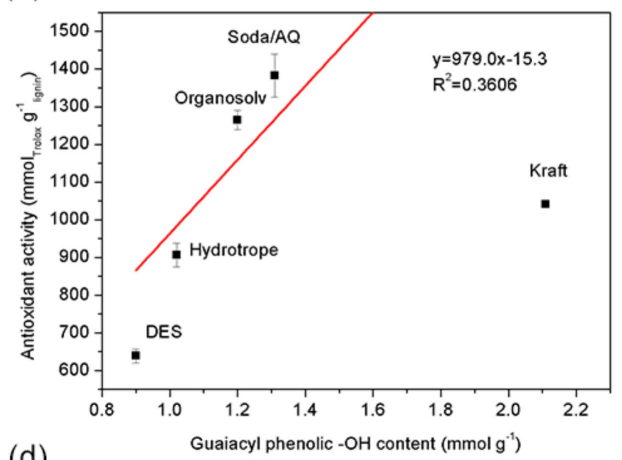

(d)

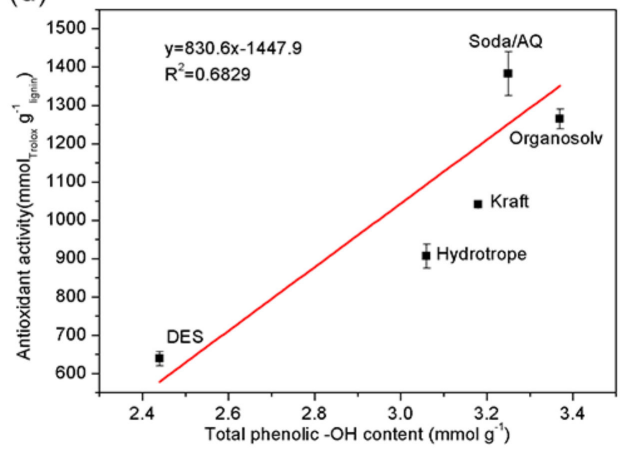

Figure 3. Relationship among antioxidant activity and the content of (a) syringyl phenolic hydroxyl groups, (b) guaiacyl phenolic hydroxyl groups, (c) p-hydroxyphenyl phenolic hydroxyl groups and (d) total phenolic hydroxyl groups of those five lignins.

The above results showed the high promise of incorporating these technical lignins into cellulose matrix to enhance their antioxidant performance. To further assess the influence of their phenolic substructures on the UV-shielding performance of the fabricated cellulose/technical lignin composite films, UV-Visible light scanning was subsequently conducted at the wavelength from 200 to $800 \mathrm{~nm}$. It was shown that all those five cellulose/lignin composite films could efficiently block the ultraviolet lights especially for UVB region (ultraviolet B, 280-315 nm) at $5 \mathrm{wt} . \%$ lignin content, while the neat cellulose film was almost transparent for all the testing ultraviolet lights (Figure 4). Although the excellent UV-shielding performance was achieved at the compromise of their transparency at visible-light region, considerable transparency was still obtained $(72 \sim 79 \%$ at $800 \mathrm{~nm}$ ) except for cellulose/ $5 \%$ organosolv lignin composite film ( $51 \%$ at $800 \mathrm{~nm}$ ).

Similar to the results of the above antioxidant activity assessment, when the transmittance values at $400 \mathrm{~nm}$ of those composite films were plotted against the contents of syringyl, guaiacyl, p-hydroxyphenyl and total phenolic hydroxyl groups of the corresponding lignins (Figure 5), the higher contents of total phenolic hydroxyl groups correlated well with their lower transmittance values at $400 \mathrm{~nm}\left(\mathrm{R}^{2}=0.8837\right)$. It was also apparent that syringyl phenolic hydroxyl groups were more successful in ultraviolet lights blocking $\left(R^{2}=0.7165\right)$ than guaiacyl phenolic hydroxyl groups $\left(R^{2}=\right.$ 0.4036). The possible reason was that methoxy groups locating on lignin aromatic rings disrupted the electrons distribution which allowed the phenolic hydroxyl groups to stay at active state. When they were exposed to ultraviolet lights [39], lower band-gap energy was required to change the 
chromophores to excited state, indicating that more ultraviolet lights with wider wavelength range could be blocked (Figure 4).

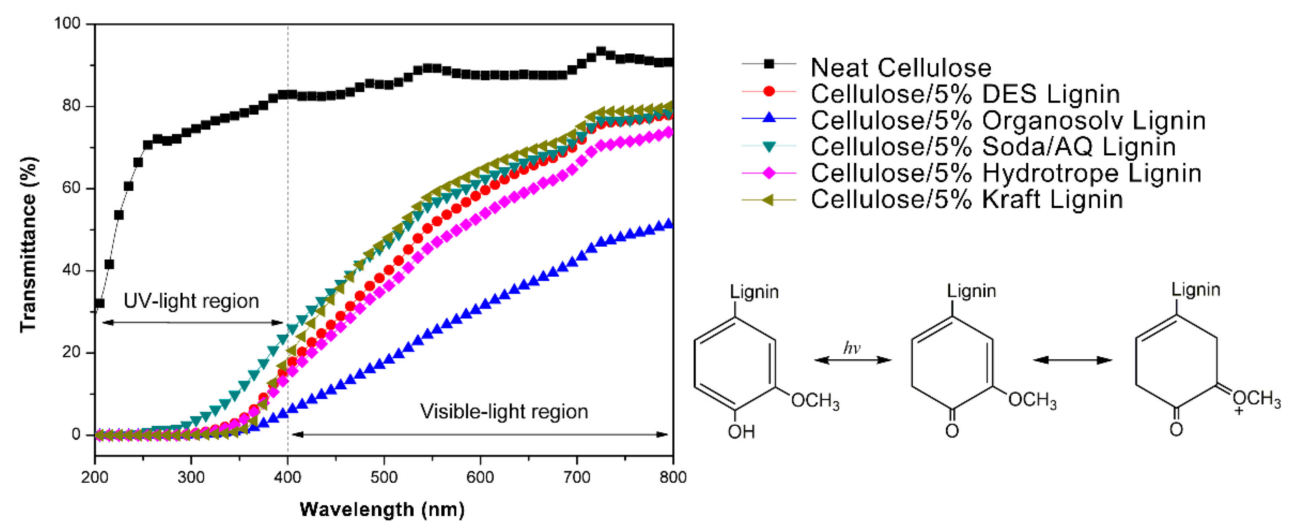

Figure 4. UV-Vis light transmittance spectra of cellulose/technical lignin composite films and possible mechanism of how methoxy groups in syringyl and guaiacyl phenolic hydroxyl groups enhanced their UV-shielding performance.

(a)

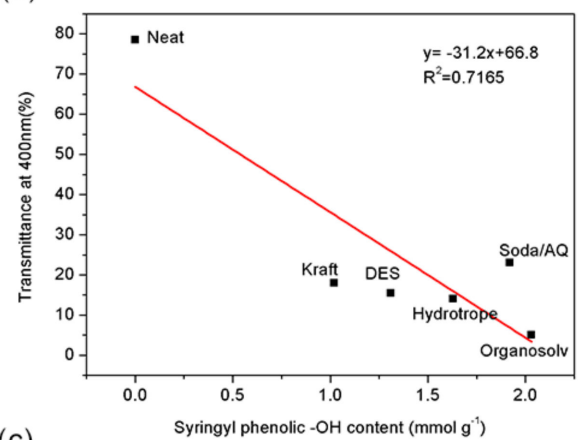

(c)

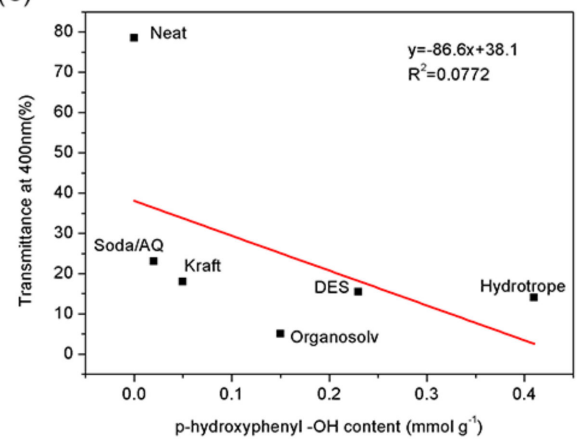

(b)

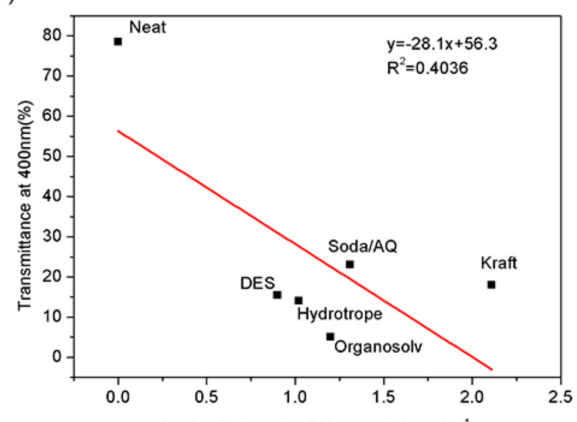

(d)

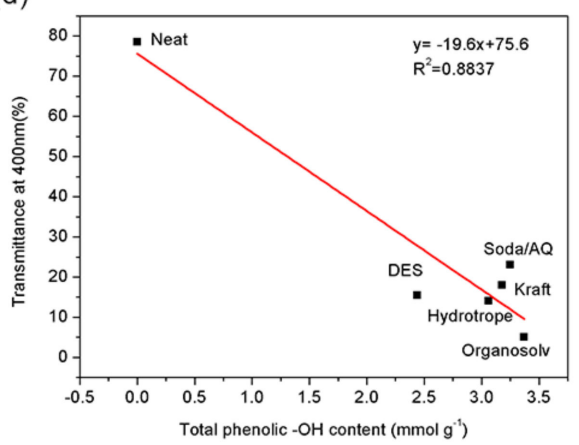

Figure 5. Relationship among transmittance at $400 \mathrm{~nm}$ of composite films and the content of (a) syringyl phenolic hydroxyl groups, (b) guaiacyl phenolic hydroxyl groups, (c) p-hydroxyphenyl phenolic hydroxyl groups and (d) total phenolic hydroxyl groups of those five lignins.

From the analysis above, it was shown that the contribution of lignin phenolic substructures to both antioxidant activity and UV-shielding property from high to low was syringyl $>$ guaiacyl $>$ p-hydroxyphenyl phenolic hydroxyl groups. Organosolv and soda/AQ lignin that exhibited considerably higher contents of syringyl phenolic hydroxyl groups could potentially endow cellulose/lignin composite films with both considerable antioxidant and UV-shielding performance. These technical lignins were more promising for downstream applications when they were used as bi-functional bio-additives for advanced packaging materials purpose such as active drugs storage. 


\section{Conclusions}

This work showed that poplar wood lignin chemical structures are highly determined by the upstream pretreatment approach selected. Both the contents and locations of lignin phenolic substructures are influential in the antioxidant and UV-shielding performance of the prepared cellulose/technical lignin composite films. Syringyl phenolic units containing additional methoxy groups were more influential in both antioxidant and UV-shielding properties. Aggressive organosolv and soda/AQ pretreatments that could effectively solubilize and fragment biomass lignin are preferred if the resulting technical lignin is used as antioxidant and UV-shielding functional bio-additive. The prepared composite films are promising for advance packaging for active drugs, long-time food storage and biodegradable packaging, etc. This work also shows a promising way to valorize lignin that is usually disposed as a by-product in a lignocellulose biorefinery.

Author Contributions: Conceptualization, D.T. and F.S.; methodology, Y.G., G.Y. and L.L.; writing-original draft preparation, Y.G., Y.Z. and D.T.; writing-review and editing, D.T., C.S. and J.H.; supervision, D.T.; project administration, S.D.; funding acquisition, C.H. and J.Z.

Funding: This work was funded by Department of Science and Technology of Sichuan Province (Grant No. 2019YJ0414), and Opening Project of State Key Laboratory of Polymer Materials Engineering (Sichuan University) (Grant No. sklpme2019-4-35).

Acknowledgments: We thank the Analytical \& Testing Center at Sichuan University for the technical help of NMR tests and Guodong Dai for the technical help for the UV-shielding test.

Conflicts of Interest: The authors declare no conflict of interest.

\section{References}

1. Mostafa, N.A.; Farag, A.A.; Abo-dief, H.M.; Tayeb, A.M. Production of biodegradable plastic from agricultural wastes. Arab. J. Chem. 2018, 11, 546-553. [CrossRef]

2. Kumar, A.; Negi, Y.S.; Choudhary, V.; Bhardwaj, N.K. Microstructural and mechanical properties of porous biocomposite scaffolds based on polyvinyl alcohol, nano-hydroxyapatite and cellulose nanocrystals. Cellulose 2014, 21, 3409-3426. [CrossRef]

3. Kumar, A.; Rao, K.M.; Han, S.S. Mechanically viscoelastic nanoreinforced hybrid hydrogels composed of polyacrylamide, sodium carboxymethylcellulose, graphene oxide, and cellulose nanocrystals. Carbohydr. Polym. 2018, 193, 228-238. [CrossRef] [PubMed]

4. Kumar, A.; Rao, K.M.; Han, S.S. Synthesis of mechanically stiff and bioactive hybrid hydrogels for bone tissue engineering applications. Chem. Eng. J. 2017, 317, 119-131. [CrossRef]

5. Siqueira, G.; Bras, J.; Dufresne, A. Cellulosic bionanocomposites: A review of preparation, properties and applications. Polymers 2010, 2, 728-765. [CrossRef]

6. Lee, J.; Mahendra, S.; Alvarez, P.J.J. Nanomaterials in the construction industry: A review of their applications and environmental health and safety considerations. ACS Nano 2010, 4, 3580-3590. [CrossRef] [PubMed]

7. Ren, J.; Wang, S.; Gao, C.; Chen, X.; Li, W.; Peng, F. TiO 2 -containing PVA/xylan composite films with enhanced mechanical properties, high hydrophobicity and UV shielding performance. Cellulose 2015, 22, 593-602. [CrossRef]

8. Tu, Y.; Zhou, L.; Jin, Y.Z.; Gao, C.; Ye, Z.Z.; Yang, Y.F.; Wang, Q.L. Transparent and flexible thin films of ZnO-polystyrene nanocomposite for UV-shielding applications. J. Mater. Chem. 2010, 20, 1594-1599. [CrossRef]

9. Wang, Y.; Li, T.; Ma, P.; Bai, H.; Xie, Y.; Chen, M.; Dong, W. Simultaneous Enhancements of UV-Shielding Properties and Photostability of Poly(vinyl alcohol) via Incorporation of Sepia Eumelanin. ACS Sustain. Chem. Eng. 2016, 4, 2252-2258. [CrossRef]

10. Tian, D.; Hu, J.; Bao, J.; Chandra, R.P.; Saddler, J.N.; Lu, C. Lignin valorization: Lignin nanoparticles as high-value bio-additive for multifunctional nanocomposites. Biotechnol. Biofuels 2017, 10, 192. [CrossRef]

11. Tian, D.; Hu, J.; Chandra, R.P.; Saddler, J.N.; Lu, C. Valorizing Recalcitrant Cellulolytic Enzyme Lignin via Lignin Nanoparticles Fabrication in an Integrated Biorefinery. ACS Sustain. Chem. Eng. 2017, 5, 2702-2710. [CrossRef] 
12. Huang, C.; He, J.; Du, L.; Min, D.; Yong, Q. Structural Characterization of the Lignins from the Green and Yellow Bamboo of Bamboo Culm (Phyllostachys pubescens). J. Wood Chem. Technol. 2016, 36, 157-172. [CrossRef]

13. Li, H.; McDonald, A.G. Fractionation and characterization of industrial lignins. Ind. Crops Prod. 2014, 62, 67-76. [CrossRef]

14. Gandolfi, S.; Ottolina, G.; Consonni, R.; Riva, S.; Patel, I. Fractionation of hemp hurds by organosolv pretreatment and its effect on production of lignin and sugars. ChemSusChem 2014, 7, 1991-1999. [CrossRef] [PubMed]

15. Yearla, S.R.; Padmasree, K. Preparation and characterisation of lignin nanoparticles: Evaluation of their potential as antioxidants and UV protectants. J. Exp. Nanosci. 2016, 11, 289-302. [CrossRef]

16. Panagiotopoulos, I.A.; Chandra, R.P.; Saddler, J.N. A two-stage pretreatment approach to maximise sugar yield and enhance reactive lignin recovery from poplar wood chips. Bioresour. Technol. 2013, 130, 570-577. [CrossRef]

17. Francisco, M.; Van Den Bruinhorst, A.; Kroon, M.C. New natural and renewable low transition temperature mixtures (LTTMs): Screening as solvents for lignocellulosic biomass processing. Green Chem. 2012, 14, 2153-2157. [CrossRef]

18. Sun, N.; Rodríguez, H.; Rahman, M.; Rogers, R.D. Where are ionic liquid strategies most suited in the pursuit of chemicals and energy from lignocellulosic biomass? Chem. Commun. 2011, 47, 1405-1421. [CrossRef]

19. Ezeji, T.; Qureshi, N.; Blaschek, H.P. Butanol production from agricultural residues: Impact of Degradation products on clostridium beijerinckii growth and butanol Characterization of bacterial and archaeal communities in air-cathode microbial fuel cells, open circuit and sealed-off reactors. Bioresour. Bioeng. 2007, 97, 1460-1469. [CrossRef]

20. Venica, A.D.; Chen, C.L.; Gratzl, J.S. Soda-AQ delignification of poplar wood. Part 1: Reaction mechanism and pulp properties. Holzforschung 2008, 62, 627-636. [CrossRef]

21. Jin, Y.; Jameel, H.; Chang, H.M.; Phillips, R. Green liquor pretreatment of mixed hardwood for ethanol production in a repurposed kraft pulp mill. J. Wood Chem. Technol. 2010, 30, 86-104. [CrossRef]

22. Mou, H.Y.; Orblin, E.; Kruus, K.; Fardim, P. Topochemical pretreatment of wood biomass to enhance enzymatic hydrolysis of polysaccharides to sugars. Bioresour. Technol. 2013, 142, 540-545. [CrossRef] [PubMed]

23. Mou,H.Y.; Heikkilä, E.; Fardim, P. Topochemistry of alkaline, alkaline-peroxide and hydrotropic pretreatments of common reed to enhance enzymatic hydrolysis efficienc. Bioresour. Technol. 2013, 150, 36-41. [CrossRef] [PubMed]

24. Sun, S.N.; Cao, X.F.; Xu, F.; Sun, R.C.; Jones, G.L. Structural features and antioxidant activities of lignins from steam-exploded bamboo (Phyllostachys pubescens). J. Agric. Food Chem. 2014, 62, 5939-5947. [CrossRef] [PubMed]

25. Wen, J.L.; Sun, S.L.; Yuan, T.Q.; Sun, R.C. Structural elucidation of whole lignin from Eucalyptus based on preswelling and enzymatic hydrolysis. Green Chem. 2015, 17, 1589-1596. [CrossRef]

26. Pu, Y.; Cao, S.; Ragauskas, A.J. Application of quantitative $31 \mathrm{P}$ NMR in biomass lignin and biofuel precursors characterization. Energy Environ. Sci. 2011, 4, 3154-3166. [CrossRef]

27. King, A.W.T.; Zoia, L.; Filpponen, I.; Olszewska, A.; Haibo, X.I.E.; Kilpeläinen, I.; Argyropoulos, D.S. In situ determination of lignin phenolics and wood solubility in imidazolium chlorides using31P NMR. J. Agric. Food Chem. 2009, 57, 8236-8243. [CrossRef] [PubMed]

28. Long, L.; Shen, F.; Wang, F.; Tian, D.; Hu, J. Synthesis, characterization and enzymatic surface roughing of cellulose/xylan composite films. Carbohydr. Polym. 2019, 213, 121-127. [CrossRef]

29. Delgado-Andrade, C.; Rufián-Henares, J.A.; Morales, F.J. Assessing the antioxidant activity of melanoidins from coffee brews by different antioxidant methods. J. Agric. Food Chem. 2005, 53, 7832-7836. [CrossRef]

30. Li, M.F.; Sun, S.N.; Xu, F.; Sun, R.C. Microwave-assisted organic acid extraction of lignin from bamboo: Structure and antioxidant activity investigation. Food Chem. 2012, 134, 1392-1398. [CrossRef]

31. An, L.; Wang, G.; Jia, H.; Liu, C.; Sui, W.; Si, C. Fractionation of enzymatic hydrolysis lignin by sequential extraction for enhancing antioxidant performance. Int. J. Biol. Macromol. 2017, 99, 674-681. [CrossRef] [PubMed]

32. Sadeghifar, H.; Venditti, R.; Jur, J.; Gorga, R.E.; Pawlak, J.J. Cellulose-Lignin Biodegradable and Flexible UV Protection Film. ACS Sustain. Chem. Eng. 2017, 5, 625-631. [CrossRef] 
33. Zhang, L.; Yan, L.; Wang, Z.; Laskar, D.D.; Swita, M.S.; Cort, J.R.; Yang, B. Characterization of lignin derived from water-only and dilute acid flowthrough pretreatment of poplar wood at elevated temperatures. Biotechnol. Biofuels 2015, 8, 203. [CrossRef] [PubMed]

34. García, A.; Toledano, A.; Andrés, M.Á.; Labidi, J. Study of the antioxidant capacity of Miscanthus sinensis lignins. Process Biochem. 2010, 45, 935-940. [CrossRef]

35. Zhang, Y.; Li, Q.; Xing, H.; Lu, X.; Zhao, L.; Qu, K.; Bi, K. Evaluation of antioxidant activity of ten compounds in different tea samples by means of an on-line HPLC-DPPH assay. Food Res. Int. 2013, 53, 847-856. [CrossRef]

36. Vijaya Kumar Reddy, C.; Sreeramulu, D.; Raghunath, M. Antioxidant activity of fresh and dry fruits commonly consumed in India. Food Res. Int. 2010, 43, 285-288. [CrossRef]

37. Piccinino, D.; Capecchi, E.; Botta, L.; Bizzarri, B.M.; Bollella, P.; Antiochia, R.; Saladino, R. Layer-by-Layer Preparation of Microcapsules and Nanocapsules of Mixed Polyphenols with High Antioxidant and UV-Shielding Properties. Biomacromolecules 2018, 19, 3883-3893. [CrossRef]

38. Pan, X.; Kadla, J.F.; Ehara, K.; Gilkes, N.; Saddler, J.N. Organosolv ethanol lignin from hybrid poplar as a radical scavenger: Relationship between lignin structure, extraction conditions, and antioxidant activity. J. Agric. Food Chem. 2006, 54, 5806-5813. [CrossRef]

39. Pouteau, C.; Dole, P.; Cathala, B.; Averous, L.; Boquillon, N. Antioxidant properties of lignin in polypropylene. Polym. Degrad. Stab. 2003, 81, 9-18. [CrossRef]

(C) 2019 by the authors. Licensee MDPI, Basel, Switzerland. This article is an open access article distributed under the terms and conditions of the Creative Commons Attribution (CC BY) license (http://creativecommons.org/licenses/by/4.0/). 